\title{
Falls in the elderly: A multifactorial problem
}

\author{
By: Susan Letvak
}

Letvak, S. (2000) Falls in the elderly: A multi-factorial problem. The Journal of Emergency Nursing, 26(5), 448-451. doi:10.1067/men.2000.110069

Made available courtesy of Elsevier: http://www.elsevier.com/wps/find/journaldescription.cws_home/623092/description\#description ***Note: Figures may be missing from this format of the document

A74-year-old woman is brought to the emergency department via stretcher by EMS after a fall at home. The paramedic informs you that the woman said she fell in the kitchen while preparing her husband's lunch. She was found lying on the kitchen floor when the paramedics arrived at the home. The patient denies having lost consciousness and complains of a sore right elbow. Her vital signs are as follows: temperature, $97.6^{\circ} \mathrm{F}$; blood pressure, $138 / 80 \mathrm{~mm} \mathrm{Hg}$; pulse, 88 beats per minute; and respirations, 16 breaths per minute. Pulse oximetry shows an oxygen saturation of $97 \%$, and her cardiac monitor reveals normal sinus rhythm. She is alert and oriented.

As you prepare to assess this woman, you mentally review your knowledge of falls in the elderly. Falls are a major problem for the elderly, occurring in almost one third of those 65 to 74 years of age and in more than half of those older than 85 years in any given year.1,2 Falls, directly or indirectly, cause $12 \%$ of all deaths in people older than 65 years. 1 Whereas only $5 \%$ of falls in the elderly result in fracture, an additional $5 \%$ to $10 \%$ result in a serious enough injury to require medical care. 1 More than two thirds of elders who fall will fall again within 6 months, and if a person older than 65 years is hospitalized for a fall, the risk of death in the year following the fall is up to $50 \% .1$ Finally, women are more likely to fall; falls occur in $42 \%$ of women aged 65 to 74 years, compared with only $20 \%$ of men in the same age group. 2

As you help the patient into a hospital gown, you question her about the fall. Identifying the cause of the fall is important, because the problem that caused the fall may be more serious than the injuries sustained in the fall. This information is necessary to prevent future falls. The patient tells you she is "getting clumsy" and has fallen "just a few times" during the past few weeks. Her husband heard her fall and would not let her get up until the ambulance came. Asking her if she was able to get up after the fall is very important. Patients who are unable to get up unassisted within 5 minutes after a fall are more likely to experience a decline in independent living status, be hospitalized, or have an early death.1

As you place an ice pack on the patient's elbow, you quickly check her body for other injuries or healing bruises that may indicate possible elder abuse. You note no other bruises, and she appears clean and well nourished. You ask her if she remembers what caused the fall, and if her husband actually saw her fall. She says that she does not really know what happened - one minute she was opening the refrigerator, and the next minute she was lying on the floor. Her 
husband was in the next room watching television and says he heard her yell out and then heard the sound of her hitting the floor. Both report that she did not lose consciousness.

After controlling her pain, you continue to get a history. You ask her about any changes in her home environment such as new carpeting, furniture, or lighting. She was wearing house slippers with nonskid soles, and the floor was clean and dry when she fell. She says the other falls occurred in the bedroom and bathroom, where there have been no changes in "over a hundred years." You then ask her about acute and chronic illnesses, as well as her medications. You know that normal physiologic changes associated with aging, such as a decline in cardiovascular, neurologic, sensory, and musculoskeletal system functioning, also contribute to increased risks for falls. She denies any history of cardiac dysrhythmias, seizures, strokes, or infections and says that she has a "little high blood pressure" and needs to watch her sugar and salt intake. Her last physical examination was 6 months ago. You also ask about alcohol use, knowing that the incidence of alcoholism in the elderly ranges from $2 \%$ to $10 \% .3$ She denies drinking alcohol at any time, except for an occasional wedding or social event. She also denies being depressed or having any memory changes. Her husband confirms that he has not noticed any physical or mental status changes. Falls often have many causes; the likelihood of falling

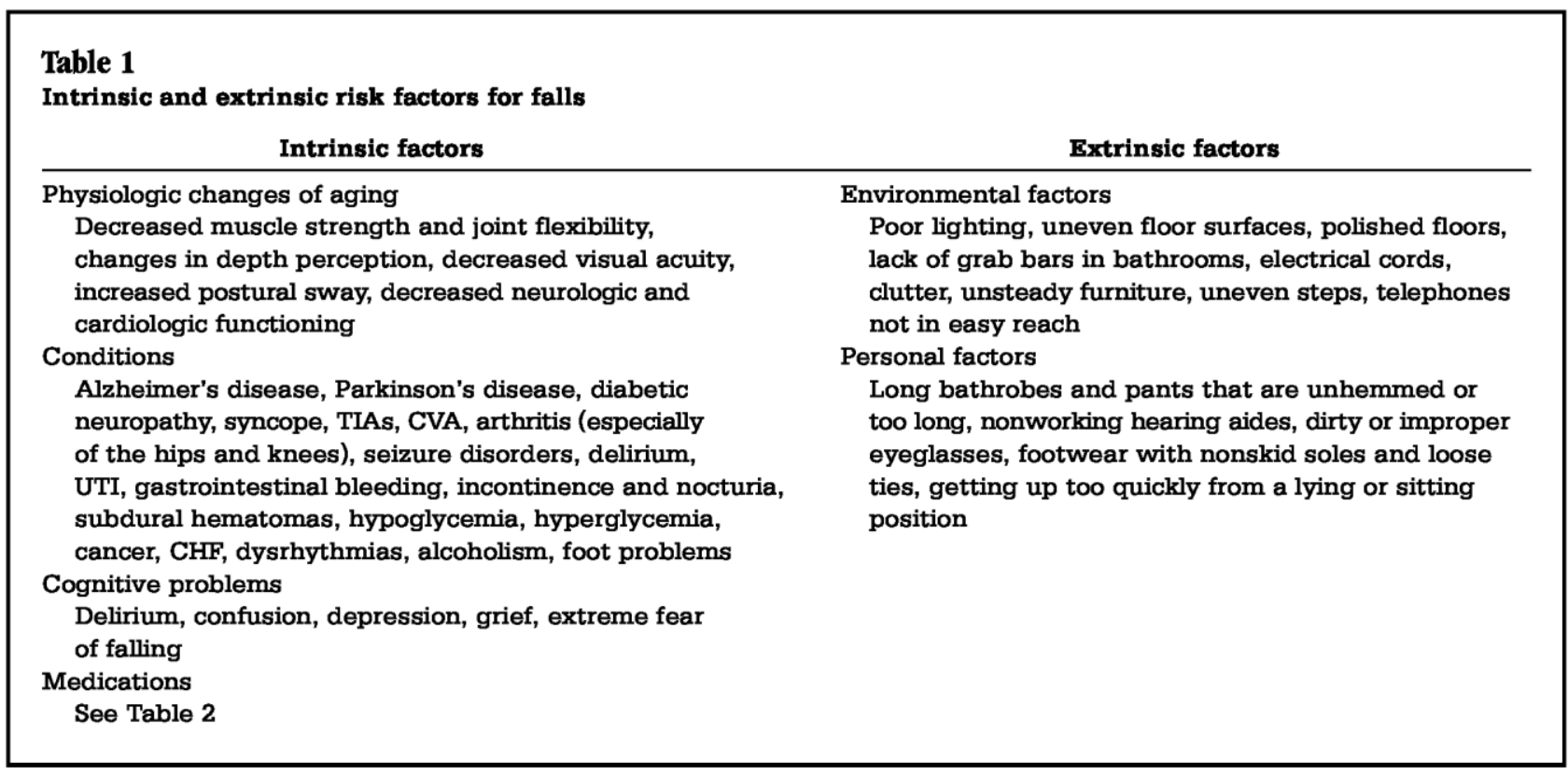

CHF, Congestive heart failure; CVA, cerebral vascular accident; TIA, transient ischemic attack; UTI, urinary tract infection.

increases with the number of risk factors present in a person4 (Table 1).

You finally ask for the names of all medications taken by the patient. As many as $35 \%$ of Americans older than 65 years take at least 1 of 20 medications that are relatively contraindicated in the elderly; $5 \%$ take 2 or more of these drugs 1 (Table 2). Medications commonly associated with increased risk for falls include diuretics, hypnotics, sedatives, narcotics, antidepressants, psychotropics, and some antihypertensive medications.4 Medications can contribute to falls by causing drowsiness, poor balance, and postural hypotension. In older 
adults, the risk of falls is greatest for persons taking medications with a half-life of more than 24 hours. 5 The patient's medications include hydrochlorothiazide, $25 \mathrm{mg}$ every morning, diltiazem hydrochloride (Cardizem CD), $120 \mathrm{mg}$ every day, and a baby aspirin ( $81 \mathrm{mg}$ ) daily. She states that she has not changed the time of day or frequency with which she takes her medications. After her husband leaves the examination room, you ask if there is anything else she is taking or any other information she would like you and the physician to know to determine why she has been falling. She replies, "Well, I have been taking a little pill my sister gave me to help me sleep. I have been very worried lately about my husband, who is having some prostate problems." She does not take a pill every night, just on the nights she is having a lot of trouble sleeping. A phone call to her sister reveals that the patient has been taking diazepam. Interestingly, a recent study found that a single dose of diazepam affects neuromuscular processing related to balance control in the elderly.6 Diazepam also has a long half-life (20 to 70 hours) and may cause dizziness or drowsiness.

\section{Nursing actions}

After a complete evaluation, results of the patient's blood work are within normal limits. Her complete blood cell count and electrolytes are within the normal range, and her stool is negative for occult blood. Results of urinalysis are normal, and her urine is clear. Her EKG shows no changes, and her serum troponin is negative. A radiograph of her elbow shows a

\begin{tabular}{|c|c|c|c|}
\hline \multicolumn{4}{|c|}{$\begin{array}{l}\text { Table } 2 \\
\text { Contraindicated medications }\end{array}$} \\
\hline Drug group & Contraindicated & Alternative & Rationale \\
\hline$\overline{\text { отC }}$ & Tylenol PM & Lorazepam & Long half-life \\
\hline Benzodiazepines & $\begin{array}{l}\text { Diazepam, flurazepam, } \\
\text { chlordiazepoxide }\end{array}$ & Lorazepam & Long half-life \\
\hline Muscle relaxants & Most & None & Sedating \\
\hline Barbiturates & Pentobarbital, secobarbital & Lorazepam & Long half-life, confusion \\
\hline Narcotics & $\begin{array}{l}\text { Propoxyphene, hydromorphone, } \\
\text { oxycodone }\end{array}$ & Hydrocodone & Long half-life, sedation \\
\hline Antidepressants & Amitriptyline & Imipramine, SSRIs & Long half-life \\
\hline Oral hypoglycemics & Chlorpropramide & Glyburide & Long half-life \\
\hline Platelet inhibitors & Dipyridamole & Aspirin & ? Effectiveness \\
\hline NSAIDs & Indomethacin & Ibuprofen & $\begin{array}{l}\text { Gastrointestinal bleeding, } \\
\text { renal toxicity }\end{array}$ \\
\hline
\end{tabular}

NSAIDs, Nonsteroidal anti-inflammatory drugs; OTC, over-the-counter; SSRIs, selective serotonin reuptake inhibitor. Modified from Baraff LJ, Della Pena R, Williams N, Sanders A. Practice guidelines for the ED management of falls in communitydwelling elderly persons. Ann Emerg Med 1997;30:480-90.

possible hairline fracture, and she will need to wear a sling for several weeks.

In light of the relatively negative results of her evaluation, the patient will be discharged. Based on the patient's admission that she had been using her sister's diazepam, the physician determines that the cause of her fall is an adverse effect of that medication. Prior to discharge you arrange for a case manager to assess the patient for potential home care needs. A referral will be made for a visiting nurse to evaluate home safety. You also provide the patient and her husband with fall prevention information and specifics about exercise classes for senior citizens 
in the area. Older people who fall often reduce their activity levels. Studies have shown that strengthening and conditioning exercises can decrease the risk of falls.2 You remind the patient to take calcium and vitamin D supplements to keep her bones strong. She should consume a diet rich in potassium, because hydrochlorothiazide may cause hypokalemia. You also provide education about her medications and the importance of never taking a medication from a friend or family member without first discussing it with her primary care provider. You remind her to have her vision and hearing checked routinely and to always wear proper footwear. Her home should be free of hazards and well lit. She should remove scatter rugs and make sure all other rugs are properly tacked to the floor. Floors should not be highly polished, and clutter should be avoided. The patient should install grab bars in her bathroom and use night-lights. She should be taught to always change her position slowly and to never quickly rise from the bed or a chair to prevent a fall from orthostatic hypotension. She also should purchase a portable telephone to be kept near her usual sitting area so she never has to rush for a ringing telephone. Before final discharge, you complete one last assessment strategy - the "Get Up and Go" test. By simply asking her to get off the stretcher and walk to the wheelchair, you can assess strength, gait, and balance. Baraff et al1,2 believe that this simple test is as important as vital signs in the evaluation of patients who fall and is the one test that is most likely not to be performed. Lastly, you remind the patient that older adults have a decrease in the average numbers of hours of sleep, often because of nocturnal awakenings and a decrease in nocturnal sleep efficiency. The patient should avoid daytime napping, retire and awaken at the same time each day, avoid consuming caffeinated and alcoholic beverages after dinner, and drink a warm beverage such as warm milk at bedtime.

\section{Follow up}

The case manager calls the patient the day after her ED visit and then weekly to see if she has had any subsequent falls. The visiting nurse also visits the home and notes that it is clean and free of major obstacles. After reading a recent study reporting deficiencies in emergency nurses' knowledge of falls in the elderly, 7 you also conduct an in-service session for your colleagues in your department.

\section{References}

1. Baraff LJ. Emergency department management of falls in the elderly. West J Med 1998;168:183-4.

2. Baraff LJ, Della Pena, RI, Williams N, Sanders A. Practice guidelines for the ED management of falls in community-dwelling elderly persons. Ann Emerg Med 1997;30:480-9.

3. Thibault JM, Maly RC. Recognition and treatment of substance abuse in the elderly. Prim Care 1993;20:155-65.

4. Wilson EB. Preventing patient falls. AACN Clin Issues 1998;9:100-8.

5. Tideiksaar R. Falls in older persons: prevention and management in hospitals and nursing homes. Boulder (CO): Tactilitics; 1993.

6. Carson TM, Gray SL, Hughes MA. Effect of a single dose of Valium on balance measure in older people. J Am Geriatr Soc 1997;45:435-40.

7. Brymer C, Cavanagh P, Bawden M, Denomy E, Wells K, Cook C, et al. Geriatric needs assessment of emergency department nurses. Gerontol Geriatr Educ 1996;17:51-64. 